\title{
Legal Aspects in Obstetric Anesthesia
}

\section{Chattopadhyay $\mathbf{S}^{1}$, Rudra $\mathrm{A}^{2}$, Ray $\mathbf{M}^{3}$, Sengupta $\mathbf{S}^{4}$, Goswami $\mathbf{S}^{5}$}

${ }^{1}$ Department of Anesthesiology, Midnapore Medical College, Midnapore, West Bengal, ${ }^{2}$ Department of Anesthesiology, K.P.C. Medical College, Kolkata, ${ }^{3}$ Calcutta National Medical College, Kolkata, ${ }^{4}$ Department of Anesthesiology, Apollo Gleneagles Hospital, Kolkata, ${ }^{5}$ Department of Gynecology and Obstetrics, Malda Medical College, Malda, West Bengal, India.

Received: April 9, 2015 ; Accepted: September 15, 2015

Obstetric anesthesia is a particularly high-risk sub-specialty of anesthesia and may lead to serious morbidities and even mortality. Good doctor-patient relation from the time of admission till discharge is the most important factor to avert future litigations. Any procedure done or planned should be clearly documented. Documentation should start with a valid consent in the patient's own language, and have all three components of voluntariness, capacity and knowledge. A 'Surgical Safety' checklist is particularly helpful in documentation and decreasing errors. Safety of the mother (and her child) is paramount. Both regional as well as general anesthesia, either inadvertently or if not administered properly may be associated with harm, and compromise safety. A significant greater proportion of lawsuit claims in obstetric anesthesia are regarding minor morbidities like headache, pain and emotional distress. However, deaths do occur and general anesthesia is associated with significantly more maternal deaths. In an unfortunate situation of death, distinction must be drawn between death from an anesthetic and death under an anesthetic. Careful personal conduct, involvement in patient care and providing standardized care should be routine practice and inculcated by everyone involved in patient care.

Keywords: adverse events; anesthesia; complications; medicolegal; obstetrics.

\section{INTRODUCTION}

Obstetrics and anesthesiology taken separately are generally considered to be high-risk medicolegal liability specialties. Therefore, it is logical to assume that obstetric anesthesia might be a particularly highrisk specialty involving an unique and challenging role involving the mother and her unborn child. This perception has been reinforced by infrequent but well publicized litigations, all involving very large compensation. ${ }^{1}$ The financial, emotional and social cost of litigation affects both the patients and health care providers. ${ }^{2}$ As the medical professions of obstetrics and anesthesiology has evolved to its current dazzling heights, the medical providers have paid greater attention to the quality of care provided to obstetric patients. ${ }^{3,4}$

The objective of this article is to provide basic information concerning the common and important legal issues that confront the obstetrics caregivers in general. The information contained in the article would help the practitioners to understand and therefore prevent or successfully defend against actions in medical malpractice claim suits.

\section{CORRESPONDENCE}

Dr Suman Chattopadhyay

Department of Anesthesiology, Midnapore Medical College,

Midnapore, West Bengal, India

Email: sumanc24@gmail.com

Phone: +91-9830234881

\section{Interpersonal relationship}

The age of specialization has brought great medical advances, but often the personal relationship the patients had with their physicians is lost. Therefore, good doctor-patient relation is perhaps the most important factor which can avert much litigation. ${ }^{5}$ Pre-anesthetic and post-anesthetic visits by the anesthesiologists and obstetricians, sympathy, good behavior, taking keen interest in the patient's complaints and apprehensions, all go a long way to boosting the patient's confidence in her caregivers. ${ }^{6}$ Once the woman and her family gain confidence in their doctor, more often than not, they are reluctant to take any legal action against any harm caused to them during the process of administering anesthesia. Documentation of all the visits is very helpful if it is necessary to mount a defense in future. ${ }^{7}$

\section{Consent for operation and anesthesia}

Before providing medical care including any clinical examination, procedure and clinical investigations, a physician is obligated to obtain consent from the patient or her surrogate decision maker if she is underage or incapable of providing consent., ${ }^{89}$ Consent for anesthesia should be on a separate paper and not on the same paper of consent for the surgery.

The law concerning consent can be said to be based on the following related principles: the ability of self-determination and the respect for individual integrity. ${ }^{10}$ 
The nature of consent consists of three separate but related elements: voluntariness, capacity, and knowledge. By voluntariness is meant the willingness of one party to participate in a transaction. By capacity is meant a sufficient degree of ability of the party to understand the nature of the transaction. By knowledge is meant that a sufficient degree of information as to the nature of the transaction is disclosed to the participant in the transaction. These three elements are thus inter-dependent rather than independent. Legal consent requires all three elements to be present and a failure of any one element means the failure of consent. The legal consequences depend on which of the elements of consent has failed. Allow the patient to give her consent in her own vernacular, which the caregiver should be able to read and understand.

In obstetric anesthesia consent is particularly important for regional blockade and analgesia during labor, where departmental protocols and complication rates are mentioned. Frequently occurring risks (even if they are of trivial nature) and serious risks (even if they are rare) should be clearly mentioned. ${ }^{6}$ In a multicultural environment effective translation should be available for patients whose first language is not English. ${ }^{11}$ A patient makes an informed consent after a discussion of the diagnosis and the proposed procedure, disclosure of risks, benefits and alternatives, and provision of an opportunity to ask questions and get answers. ${ }^{2}$ This decision making aids may be used in individual and group setting in a variety of formats, such as print, video and interactive devices. ${ }^{12}$ Good judgment on part of physicians goes a long way to find a balance between frightening the patient and informing the patient. ${ }^{6}$ A procedure carried out on a patient without the consent of the patient, is prima facie an infringement of that patient's right and may give rise to judgment against the concerned physician(s) in criminal and civil law. ${ }^{13,14}$ Criminal prosecutions are usually brought by the state and are punitive; civil actions are usually brought by the aggrieved individual and are complementary.

\section{Consent (minor patient)}

For most health care decisions, a parent is still required to provide consent for the medical treatment of a minor patient. ${ }^{15}$ Thus, health care providers should typically obtain consent from the minor's parent before providing anesthesia. However in developed countries minors are giving their individual consent for sexual and reproductive care, including abortion and delivery as well as access to mental health and deaddiction services. ${ }^{16}$ Nevertheless, the minors consent will include a detailed documentation of the minor's age, maturity, intelligence, training, experience, economic independence and freedom from parental control.

\section{Consent for labor analgesia}

The anesthesiologist and obstetrician should discuss the various options of labor analgesia with the patients before she is in distressing pain. ${ }^{17}$ Unfortunately, the anesthesiologist often first encounters the patient when she is in severe pain. Although the anesthesiologist may tailor the consent process according to the circumstances, the presence of maternal pain and distress does not obviate the need for the anesthesiologist to present a frank discussion of the risks of anesthesia on the baby and labour, as well as the alternatives. ${ }^{18}$

\section{Refusal of consent}

The patient may at times refuse any sort of surgical procedure or continue use of substances which may harm her or the fetus. This situation may cause tremendous tension for the health care provider, the patient and her relatives. In this situation every attempt should be made to convince the patient of the significant risks involved due to her unreasonable manner. As a last resort, intervention of the court may be sought for to restrict the irrational behavior of the patient which in every probability will lead to harm. ${ }^{19}$

\section{Preoperative preparation}

Before administration of anesthesia, anesthesiologist must know the co-existing disease and treatment received by the patient. Patients should be in optimal physical condition for all elective surgery. If any adverse effect occurs, it is the onus of the anesthesiologist to justify as to why anesthesia was administered if there was any scope of rectifying the associated comorbidity. ${ }^{20}$ In conditions where the disability is not likely to improve further, and the surgery cannot be deferred, the anesthesiologist and obstetrician must have the patient's "consent" that if he/she thinks it necessary depending on his/her own experience and facilities available, he/she should seek the help of a second consultant and transfer to the appropriate facilities (e.g. critical care units) after the operation if required. ${ }^{21}$ 


\section{Standard of anesthesia}

In 1986, the Delegates of American Society of Anesthesiologists and American College of Obstetrics and Gynecology approved a joint statement entitled "Optimal Goals for Anesthesia Care in Obstetrics". This policy oriented document recognized the need for: ${ }^{2}$

- Availability of a person qualified to administer an appropriate anesthetic whenever necessary.

- Availability of a person qualified to maintain support of vital functions in any obstetric emergency.

- Appointment of a qualified anesthesiologist to be responsible for to all anesthetic administered to manage the infrequent but occasionally lifethreatening complications of regional anesthesia such as respiratory and cardiovascular failure, toxic local anesthetic convulsions or vomiting and aspiration.

- Availability of a qualified obstetrician during administration of anesthesia. Lumbar or caudal epidural anesthesia, spinal anesthesia and/or general anesthesia should not be administered until the patient has been examined, and the fetal status and the progress of labor evaluated by a qualified obstetrician who is readily available to supervise the labor and to deal with any obstetric complications that may arise.

- Availability of equipment facilities and support personnel.

- Availability of properly equipped and staffed recovery room capable of receiving and caring for all patients recovering from regional or general anesthesia.

- Immediate availability of personnel responsible to resuscitate the depressed neonate. The surgeon and the anesthesiologist are responsible for the mother and may not be able to leave her to care for the neonate even when a regional anesthetic is functioning adequately.

- Preferably an anesthesiologist with special training or experience in obstetric anesthesia should direct the obstetric anesthesia service.

\section{Guidelines for regional anesthesia in obstetrics ${ }^{22}$}

The guidelines apply to the use of regional anesthesia or analgesia in which local anesthetics are administered to the parturient during labor and delivery.

- Regional anesthesia should be initiated and maintained only in location in which appropriate resuscitation equipment and drugs are immediately available to manage procedure related problems. Resuscitation equipment should include: (a) source of oxygen and suction, (b) equipment to maintain an airway and perform endotracheal intubation, (c) a means to provide positive pressure ventilation, and (d) drugs and equipment for cardiopulmonary resuscitation.

- A physician who has been approved through the institutional credential process should initiate regional anesthesia.

- Regional anesthesia should not be administered until: (a) the patient has been examined by a qualified individual, and (b) the maternal and fetal status and progress of labor have been evaluated by an obstetrician who is readily available to supervise the labor and manage any obstetric complications that may arise.

- An intravenous infusion should be established before the initiation of regional anesthesia and maintained throughout the duration of the regional anesthesia.

- Vital signs of the patient and the fetal heart rate should be monitored and documented by a qualified individual. When extended regional blockade is administered for complicated vaginal delivery, the standards for basic anesthetic monitoring should be applied.

- Regional anesthesia for caesarean delivery requires that the standards for basic anesthetic monitoring (blood pressure, pulse rate, respiratory rate, oxygen saturation, and electrocardiography) be applied.

- An anesthesiologist should remain available until the patient's post-anesthesia condition is satisfactory and stable.

Liability profiles in obstetric anesthesia (The American Society of Anesthesiologists closedclaim project)

Despite the significant limitations of closed claim studies, such efforts do provide information that cannot be obtained in other ways. One of the most striking observations one can make when comparing 
the obstetric lawsuit claims to non-obstetric claims is that the obstetric claims contain a significantly higher proportion of what one might consider relatively minor injuries, i.e. headache, back pain, pain during anesthesia, and emotional distress. ${ }^{23} \mathrm{~A}$ decrease in major claims and increase in minor claims correlates temporarily with decreased use of general anesthesia and increased use of regional anesthesia in obstetrics. ${ }^{24}$ However, the incidence of major events claims is not too dissimilar (Table 1).

Table 1. Comparison of obstetric versus non-obstetric claims. $^{23}$

\begin{tabular}{|lll|}
\hline Major Claims & $\begin{array}{l}\text { Obstetric } \\
\text { claim (\%) }\end{array}$ & $\begin{array}{l}\text { Non-Obstetric } \\
\text { claims (\%) }\end{array}$ \\
\hline Death & $22^{* *}$ & 33 \\
Patient brain death & 9 & 13 \\
Aspiration & 5 & 3 \\
Nerve damage & 16 & 17 \\
Minor Claims & & \\
Headache & $18^{* *}$ & 2 \\
Pain during anesthesia & $11^{* *}$ & 1 \\
Back pain & $12^{* *}$ & 1 \\
Emotional distress & $10^{* *}$ & 4 \\
\hline
\end{tabular}

** $\mathrm{P}<0.01$

\section{Anesthesia related injuries}

Table 2 lists all injuries or complications that had a frequency of $5 \%$ or greater in the obstetric lawsuit files, as well as the type of anesthesia that resulted in the injury. Maternal death and neonatal brain damage were the most common injuries. A significant greater proportion of the maternal deaths involved general anesthesia during caesarean delivery. ${ }^{25-28}$

The most striking finding in Table 2 is that the maternal lawsuit files contain a much higher proportion of relatively minor injuries. ${ }^{23,29}$ Obstetric patients may be at greater risk for some of these complications. ${ }^{30}$

\section{Events leading to injuries}

The closed claim data reveal information about the events that lead to the injury. The most commonly identified mechanism of injury or damaging event for both obstetric and non-obstetric files are listed in Table $3 .{ }^{31-34}$

Table 3. Common events leading to damage in anesthesia lawsuits.

\begin{tabular}{|c|c|c|c|c|}
\hline & $\begin{array}{l}\text { Non } \\
\text { Obstetric } \\
\text { files } \\
(\mathrm{n}=3099)\end{array}$ & $\begin{array}{l}\text { Obstetric } \\
\text { Files } \\
(n=344)\end{array}$ & $\begin{array}{l}\text { Obstetric } \\
\text { Regional } \\
(\mathrm{n}=290)\end{array}$ & $\begin{array}{l}\text { Obstetric } \\
\text { General } \\
(\mathrm{n}=133)\end{array}$ \\
\hline $\begin{array}{l}\text { Respiratory } \\
\text { System }\end{array}$ & $30 \%(914)$ & $18 \%(80)$ & $\begin{array}{l}6 \% \\
(16)\end{array}$ & $\begin{array}{l}47 \% \\
(63)\end{array}$ \\
\hline $\begin{array}{l}\text { Difficult } \\
\text { intubation }\end{array}$ & $6 \%(181)$ & $7 \%(30)$ & $\begin{array}{l}<0.5 \% \\
\text { (1) }\end{array}$ & $\begin{array}{l}22 \% \\
(29)\end{array}$ \\
\hline Aspiration & $2 \%(52)$ & $4 \%(17)$ & $1 \%$ & $11 \%$ \\
\hline $\begin{array}{l}\text { Esophageal } \\
\text { intubation }\end{array}$ & $6 \%(178)$ & $2 \%(10)$ & $\begin{array}{l}(2) \\
1 \% \\
(2)\end{array}$ & $\begin{array}{l}(15) \\
6 \% \\
(8)\end{array}$ \\
\hline $\begin{array}{l}\text { Inadequate } \\
\text { ventilation/ } \\
\text { oxygenation }\end{array}$ & $9 \%(266)$ & $2 \%(9)$ & $\begin{array}{l}2 \% \\
(6)\end{array}$ & $\begin{array}{l}2 \% \\
(2)\end{array}$ \\
\hline Bronchospasm & $1 \%(42)$ & $2 \%(7)$ & $\begin{array}{l}1 \% \\
(2)\end{array}$ & $\begin{array}{l}4 \% \\
(5)\end{array}$ \\
\hline $\begin{array}{l}\text { Premature } \\
\text { extubation }\end{array}$ & $1 \%(42)$ & $1 \%(3)$ & $\begin{array}{l}0 \% \\
(0)\end{array}$ & $\begin{array}{l}2 \% \\
(3)\end{array}$ \\
\hline $\begin{array}{l}\text { Airway } \\
\text { obstruction }\end{array}$ & $3 \%(82)$ & $\begin{array}{l}<0.5 \% \\
(2)\end{array}$ & $\begin{array}{l}<0.5 \% \\
\text { (1) }\end{array}$ & $\begin{array}{l}1 \% \\
(1)\end{array}$ \\
\hline $\begin{array}{l}\text { Inadequate } \\
\mathrm{FiO}_{2}\end{array}$ & $<0.5 \%(5)$ & $\begin{array}{l}<0.5 \% \\
(2)\end{array}$ & $\begin{array}{l}<0.5 \% \\
\text { (1) }\end{array}$ & $\begin{array}{l}1 \% \\
(1)\end{array}$ \\
\hline Convulsion & $2 \%(45)$ & $9 \%(35)$ & $\begin{array}{l}12 \% \\
(16)\end{array}$ & $\begin{array}{l}3 \% \\
(4)\end{array}$ \\
\hline $\begin{array}{l}\text { Equipment } \\
\text { problems }\end{array}$ & $10 \%(315)$ & $6 \%(27)$ & $\begin{array}{l}8 \% \\
(16)\end{array}$ & $\begin{array}{l}3 \% \\
(4)\end{array}$ \\
\hline $\begin{array}{l}\text { Cardio } \\
\text { vascular } \\
\text { system }\end{array}$ & $9 \%(287)$ & $4 \%(18)$ & $\begin{array}{l}4 \% \\
(16)\end{array}$ & $\begin{array}{l}3 \% \\
(4)\end{array}$ \\
\hline $\begin{array}{l}\text { Wrong } \\
\text { dosage }\end{array}$ & $4 \%(113)$ & $3 \%(13)$ & $\begin{array}{l}2 \% \\
(16)\end{array}$ & $\begin{array}{l}5 \% \\
(7)\end{array}$ \\
\hline
\end{tabular}

\section{Responsibility assignment for physical injuries}

Not infrequently when an adverse reaction occurs during administration of anesthesia, the question

Table 2. Most common injuries in the obstetric anesthesia. ${ }^{23}$

\begin{tabular}{|llllll|}
\hline & $\begin{array}{l}\text { Obstetric files } \\
(\mathbf{n = 7 0 6 )}\end{array}$ & $\begin{array}{l}\text { Regional anesthesia } \\
\mathbf{( n = 4 8 0 )}\end{array}$ & $\begin{array}{l}\text { General } \\
\text { anesthesia } \\
(\mathbf{n = 1 9 3 )}\end{array}$ & $\begin{array}{l}\text { Cesarean } \\
\text { Section } \\
(\mathbf{n = 4 7 3})\end{array}$ & $\begin{array}{l}\text { Vaginal delivery } \\
(\mathbf{n = 2 3 2})\end{array}$ \\
Maternal death & $17 \%(117)$ & $9 \%(43)^{*}$ & $37 \%(71)$ & $21 \%(100)^{*}$ & $7 \%(17)$ \\
Neonatal brain damage & $18 \%(124)$ & $15 \%(71)^{*}$ & $24 \%(46)$ & $18 \%(86)$ & $16 \%(38)$ \\
Headachex & $14 \%(99)$ & $19 \%(94)^{*}$ & $2 \%(3)$ & $9 \%(45)^{*}$ & $23 \%(54)$ \\
Maternal nerve damage & $14 \%(96)$ & $18 \%(90)^{*}$ & $3 \%(5)$ & $12 \%(55)$ & $18 \%(41)$ \\
Pain during anesthesia & $8 \%(53)$ & $10 \%(48)^{*}$ & $2 \%(3)$ & $10 \%(47)^{*}$ & $3 \%(6)$ \\
Back pain & $10 \%(69)$ & $14 \%(69)^{*}$ & $0 \%(0)$ & $6 \%(29)$ & $17 \%(40)$ \\
Maternal brain damage & $7 \%(50)$ & $6 \%(28)$ & $9 \%(18)$ & $8 \%(40)$ & $4 \%(10)$ \\
Emotional distress & $8 \%(53)$ & $8 \%(40)$ & $7 \%(13)$ & $8 \%(38)$ & $6 \%(15)$ \\
Neonatal death & $6 \%(44)$ & $5 \%(24)$ & $8 \%(15)$ & $7 \%(33)$ & $5 \%(11)$ \\
Aspiration pneumonitis & $4 \%(26)$ & $1 \%(4)^{*}$ & $11 \%(21)$ & $4 \%(21)$ & $2 \%(4)$ \\
\hline
\end{tabular}


arises as to who is legally responsible. ${ }^{35}$ A lawyer from the plaintiff will try to implicate anybody who comes in contact with the patient. Anesthesiologists, nurses, surgeons and hospitals all have been served notices individually as well as collectively. ${ }^{36}$ An anesthesiologist who administers anesthesia is alone responsible for the outcome due to anesthesia. ${ }^{37} \mathrm{~A}$ mistake or a bad outcome does not denote negligence or malpractice. ${ }^{38}$

\section{Anesthetic death}

A distinction must be drawn between death from an anesthetic and a death under an anesthetic. ${ }^{39}$ An anesthetized patient may die from the action of the anesthetic, from surgical shock, from hemorrhage, or from a combination of these or other causes. She may die from an accident consequent upon the administration of the anesthetic; for example asphyxia due to aspiration of vomit. ${ }^{40}$

Every death under an anesthetic should be reported to the appropriate authority including police. The surgical team will not leave the theatre and will not remove anything used for the patient till the police arrives and gives consent to do so. In case of any obscurity, the surgical team should insist on an autopsy for their own safety. ${ }^{21,27}$

\section{Documentation}

Apart from the consent of the patient, records of the relevant history of the patient and clinical examination done at admission should be properly documented at all times deemed necessary for the particular patient. For operative procedures a detailed preoperative evaluation, intra-operative management (anesthesia and surgical procedures, continuous physiologic monitoring, use of fluid and blood product and drugs administered) including details of any critical incidents, as well as a detailed postoperative care and advice should be diligently noted. ${ }^{17}$ For labor analgesia details of the analgesic procedure, record of continuous maternal and fetal physiologic monitoring, use of fluids and other drugs, and any critical incidents should be documented in a concise but complete manner. ${ }^{2,17}$

Proper documentation is invaluable for medicolegal purpose and serves as an essential form of communication between health care professionals. ${ }^{41}$

\section{Recommendations}

A careful practitioner will, in most cases, not be exposed to any legal action if he observes the following recommendations.

Always make sure of the preoperative checkup and preparation before the administration of anesthesia.

The administration of anesthetic should not be undertaken without the consent of the patient, or her guardian, if she is a minor or unconscious, after the nature and consequence of the operation have been explained to her guardian. ${ }^{42,43}$ However, in cases of an emergency where delay is dangerous, operation under anesthesia may be performed without the consent of the patient or her relative or guardian. ${ }^{44,45}$ Anesthesiologists are protected against any harm caused to a patient in good faith. ${ }^{46}$

Postoperative care of an operated patient is legal responsibility of an anesthesiologist. If necessary, proper care by another consultant colleague must be arranged. Furthermore, he should not fail to attend an urgent call from the patient whom he is treating. ${ }^{47}$

An anesthesiologist should be a duly qualified person and he/she should always administer a generally accepted anaesthetic, after he had used reasonable care and skill in administering it. ${ }^{48}$

Avoid errors whenever possible. The 'surgical safety checklist' initiated by the World Health Organization have lead to remarkable benefits of outcome in surgical patients as well as improved communication among the surgical team, and thus quality of care. ${ }^{49}$ This checklist is to be completed in three stages: the period before induction of anesthesia (sign in), the period after induction and before surgical incision (time out), and again at the period during or immediately after wound closure but before removing the patient from the operating room (sign out). Application of checklists based on the WHO surgical safety checklist outside the operating theatre has also led to improved patient outcome. ${ }^{50}$

In the case of death from anesthesia, the anesthesiologist or surgeon should at once report the matter to the police for holding a public enquiry.

Issues that have led to controversies and patientcaregiver tussle in obstetric delivery rooms are allowing presence of a partner/spouse/support person inside the delivery area, videotaping the birth process and a 'bad baby' outcome. All these conflicts are emotional and traumatic to the patient, her family as well as to the care giving team. ${ }^{51,52}$ Clear hospital guidelines should be in place regarding these issues. 


\section{CONCLUSIONS}

Litigation has a very grave impact on obstetric anesthesia practice. The physicians have one eye on the courts of law instead of both eyes on the patient. This leads to defensive practice by doctors, increasing the burden of investigations, raising the pressure on health care system, infrastructure, and expenses. Litigation cannot be totally prevented.

To recover the medical malpractice, the person bringing the law suit (the plaintiff) must establish all of the following elements: (a) the existence of the physician's duty to the patient, (b) the applicable standard of care and its violation, (c) a causal connection between the physician's violation of the

\section{REFERENCES}

1. The Joint Commission. "What did the doctor say?" Improving health literacy to protect patient safety 2007. [cited 2014 March 18]. Available from http://www.joint commission.org/ assets/1/18/improving_health_literacy.pdf.

2. Williams MS. Davies JM, Ross BK. Medicolegal Issues in Obstetric Anesthesia. In: Chestnut DH, Polley LS, Tsen LC, Wong CA, editors. Obstetric Anesthesia Principles and Practice. $4^{\text {th }}$ ed. Philadelphia, USA: Elsevier Mosby; 2009. p.727-46

3. Eastaugh SR. Reducing litigation costs through better patient communication. Physician Exec. 2004;30: 36-8.

4. American Society of Anesthesiologists. ASA policy statement on practice parameters. [cited 2014 March 18]. Available from http://www2.asahq.org/publications/p-106-asa-standardsguidelines-and-statements.aspx.

5. Furrow BR, editor. Liability and Quality Issues in Health Care. $4^{\text {th }}$ ed. St. Paul, MN: West Group; 2001.

6. Davies JM, Ross BK. Informed Consent, Documentation and Medicolegal Issues. In: Bucklin BA, Gambling DR, Wlody D; editors. A Practical Approach to Obstetric Anesthesia. $1^{\text {st }}$ ed. PA, USA: Lippincott Williams \& Wilkins; 2009. p. 69-79.

7. Bush DJ. A comparison of informed consent for obstetric anesthesia in the USA and the UK. Int J Obstet Anesth. 1995; $4: 1-6$.

8. Plessis HD, Johnstone C. Ethics and medico-legal aspects of obstetric anesthesia. Anesth Intens Care Med. 2007; 8;337-9.

9. Agell I. Capacity and consent. J R Soc Med. 2003;96:157.

10. Davies JM, Posner KL, Lee LA, Cheney FW, Domino KB. Liability associated with obstetric anesthesia: a closed claims analysis. Anesthesiology. 2009; 110(1):131-9.

11. Lupton M. Informed consent: can a patient ever be fully informed? Curr Opin Obstet Gynecol. 2005;17:601-4.

12. O'Connor AM, Wennberg JE, Legare F, Llewellyn-Thomas HA, Moulton BW, Sepucha KR, et al. Toward the 'tipping point': decision aids and informed patient choice. Health Aff. 2007;26:716-25.

13. Rosovaky FA, editor. Consent to Treatment: A Practical Guide. $3^{\text {rd }}$ ed. Gaithgersburg, MD: Aspen; 2001. standard of care, and (d) the resulting compensable injury to the patient. Therefore, anesthesia care providers should attempt to organize themselves in a manner such that patients will not be motivated to bring a suit for an unexpected outcome. Suggestions to avoid obstetric claims include careful personal conduct, involvement in prenatal, early pre-anesthetic evaluation as well as providing realistic expectations and practicing at or above the standard of care.

\section{DISCLOSURE}

The authors report no conflicts of interest in this work.

No violation of human rights and safety.

Funding: Nil

14. Annas GJ. Protecting the liberty of pregnant patients. N Engl J Med. 1987; 316:1213-4.

15. CBS News. Debate reviewed on mother's rights. May 19 2004. [cited 2014 March 18]. Available from http://www. cbsnews.com/stories/ 2004/05/ 19/ health/main618535.stml? source $=$ search_story.

16. Holder AR. Minor's rights to consent to medical care. JAMA. 1987;257:3400-2.

17. American Society of Anesthesiologists Task Force on Obstetric Anesthesia. Practice guidelines for obstetric anesthesia: an updated report. Anesthesiology. 2007;106:84363.

18. Patee C, Ballantyne M, Milne B. Epidural analgesia for labour and delivery: informed consent issues. Can J Anaesth. 1997:44:918-23.

19. American College of Obstetricians and Gynecologists Committee on Ethics. Maternal decision-making, ethics and the law. Obstet Gynecol. 2005; 106:1127-37.

20. Kuczkowski KM. Informed consent, the parturient, and obstetric anesthesia. J Clin Anesth. 2003;15:573-4.

21. Ganguly Mukherjee G, Malhotra N, editors. Medicolegal Aspects in Obstetrics and Gynaecology. New Delhi: Jaypee Brothers Medical Publishers (P) Ltd; 2008.

22. Zundert AV, Ostheimer GW, editors. Pain relief and anesthesia in obstetrics. New York: Churchill Livingstone; 1996.

23. Ross BK. ASA closed claims in obstetrics: lessons learned. Anesthesiol Clin North America. 2003; 21:183-97.

24. Davies JM. Obstetric anesthesia closed claims. Trends over last three decades. ASA Newsl. 2004;68:12-4.

25. Hawkins JL, Koonin LM, Palmer SK, Gibbs CP. Anesthesiarelated deaths during obstetric delivery in the United States, 1979-90. Anesthesiology. 1997; 86:277-84.

26. Endler GC, Mariona FG, Sokal RJ, Stevenson LB. Anesthesia related maternal mortality in Michigan. Am J Obstet Gynecol. 1988;159:87-93.

27. Rudra A, Mondal M, Acharya A, Nayak S, Mukherjee S. Anaesthesia related maternal mortality. J Indian Med Assoc. 2006;104:312-6.

28. Rudra A. Airway management in obstetrics (Postgraduate Number). Ind J Anaesth. 2005; 49:328-35. 
29. Hawkins JL, Gibbs CP, Orleans M, Martin-Salvaj G, Beaty B. Obstetric anesthesia workforce survey, 1981 versus 1992. Anesthesiology. 1997;87:135-43.

30. Bucklin BA, Hawkins JL, Anderson JR. Obstetric anesthesia workforce survey: twenty-year update. Anesthesiology. 2005;103:645-53.

31. Joanna MD. Obstetric anesthesia closed claims - trends over last three decades. ASA Newsl. 2004; 68:6.

32. Chadwick HS. Obstetric anesthesia closed claims update ASA Newsl. 1993; 57:12-8.

33. Chadwick HS. An analysis of obstetric anesthesia cases from the ASA closed claim database. Int J Obstet Anesth. 1996;5:258-63.

34. Chadwick HS, Gunn HS, Ross BK, Glosten B, Posner K. Nerve injury and regional anesthesia in obstetrics - a review of the ASA closed claims project database. Anesthesiology. 1995;83: A 951.

35. Hawkins GB, Clayton EW, Githens PB, Sloan FA. Factors that prompted families to file medical malpractice claims following perinatal injuries. JAMA. 1992;267:1359-63.

36. Modell JH. Who is captain of anaesthesia ship (editorial). Arch Surg. 1998; 121:753.

37. Ganguly Mukherjee G, Soonawala RP, Tank DK, editors. Medico-legal problems in administering anaesthesia in obstetrics and gynaecological cases. New Delhi: Jaypee Brothers Medical Publishers (P) Ltd; 1997.

38. Bowyer EA, Paulson L. Informed consent allegations affect all specialties. Risk Manage Found Forum. 1986;7:3-6.

39. Subrahmanyam BV, editor. Modi's medical jurisprudence and toxicology. New Delhi: Butterworths; 2001

40. Hawkins JL. Anesthesia-related maternal mortality. Clin Obstet Gynecol. 2003:46:679-87.
41. Palmer SK, Gibbs CP. Risk management in obstetric anesthesia. Int Anesthesiol Clin. 1989;27:188-9.

42. Sanford S. Informed consent: the verdict is in. ASA Newsl. 2006;70:7.

43. Appelbaum PS. Clinical practice: Assessment of patients' competence to consult to treatment. $\mathrm{N}$ Engl J Med. 2007;357:1834-40.

44. Kragie JF, Mather K. Standard of care and specialties. ASA Newsl. 2002;66: 24-5.

45. Mishkin DB, Povar GJ. Decision making with pregnant patients: a policy born of experience. Joint Comm J Qual Improv. 1993;89:80-4.

46. Braveman FR, editor. Obstetric and Gynecologic Anesthesia: The Requisite in Anesthesiology. Philadelphia: Elsevier Mosby; 2006.

47. American Medical Association. AMA code of medical ethics. [cited 2014 March 18]. Available from http://www.ama-assn. org/ama/pub/category/2498.html/

48. Hyams AL, Brandenburg JA, Lipsitz SR, Shapiro DW, Brennan TA. Practice guidelines and malpractice litigation: a two-way street. Ann Intern Med. 1995; 122:450-5.

49. Walker IA, Reshamwalla S, Wilson IH. Surgical safety checklists: do they improve outcomes? $\mathrm{Br} \mathrm{J}$ Anaesth. 2012;109 (1):47-54

50. Braham DL, Richardson AL, Malik IS. Application of the WHO surgical safety checklist outside the operating theatre: medicine can learn from surgery. Clin Med (Lond). 2014;14(5),468-74.

51. Hickson GB, Clayton EW, Githens PB, Sloan FA. Factors that prompted families to file medical malpractice claims following perinatal injury. JAMA. 1992;267:1359-63.

52. Holzer JF. The advent of clinical standards for professional liability. QRB Qual Rev Bull. 1990;16:71-9. 